\title{
ELAINE HALLEY: 'THE FUTURE - 3D PLANNING BUT WITH THE FACE IN MOTION'
}

Ahead of her presentation at the 2015 British Dental Conference and Exhibition, the $B D J$ caught up with Elaine Halley, to find out more about the changing face of cosmetic dentistry, Digital Smile Design and the vision behind her dental spa.

\section{You originally studied biology at university - how did this turn into dentistry?}

I had never considered dentistry as a career option as my concept of it was 'drilling and filling'. I then met some dental students in their second year in which they were studying anatomy and doing the dissection of the head, neck and thorax. I was fascinated - and realised that it was a qualification in dental surgery. I spent some time shadowing my dentist back at home and applied to transfer. My application was accepted and I've never looked back!

\section{Since you qualified, how has aesthetic dentistry changed?}

When I qualified in 1992, there was no real conversation about aesthetic dentistry. We had learnt about composite and porcelain veneers though - and interestingly veneers were taught as a reversible option in those days! Funny how things come full circle. The advances in porcelain technology, diagnosis and smile design have all allowed us to plan comprehensively and consider the smile as well as the restorative needs of the patient.

\section{The ethos behind Cherrybank Dental Spa is to bring excellent customer service to dentistry - how did you come up with the concept?}

My parents had a Woollen Mill which was located on the 18th Green of the St Andrews Old Course. They were used to serving American and Japanese tourists with high expectations and customer service was a key part of their business ethic. In addition, I wasn't a good dental patient as a child! The
'The concept of a dental spa is about making every aspect of the patient experience as comfortable as possible...' combination of these two factors meant that I developed a vision of having a practice which didn't feel like traditional dentistry, was quirky and a bit different in order to relax patients. I also studied and worked in the US, where dentists were far ahead of us at the time in terms of customer service.

Did you face any challenges when setting up Cherrybank Dental Spa?

When I first started in Perth in 1995 I called my practice Cherrybank Family Dental Health Centre. From a very early stage we adopted the hygiene exam model, which is a prevention based model where all recall or check-up patients are booked in the hygiene book and the dentist moves between patients. It was a progression in my education and many trips to study in the States where we discovered the concept of dental spa. The concept of a dental spa is about making every aspect of the patient experience as comfortable as possible and as unlike a visit to the dentist as possible. This extends to thinking about the environment, including smell and distractions from the noises of treatment such as DVD glasses or noise-reducing headphones. We also offer 'comforts' such as moisturising paraffın hand-wax which can run alongside dentistry and provide the added benefit of lovely soft hands as well as a clean and healthy mouth! This concept fits in well with my initial desire to help nervous patients to cope with dental treatment. Dental spa is about being patient centric and considering patient comfort before, during and after treatment. Although it could be conceived as a strange term that needs explaining, we find that patients really enjoy the concept

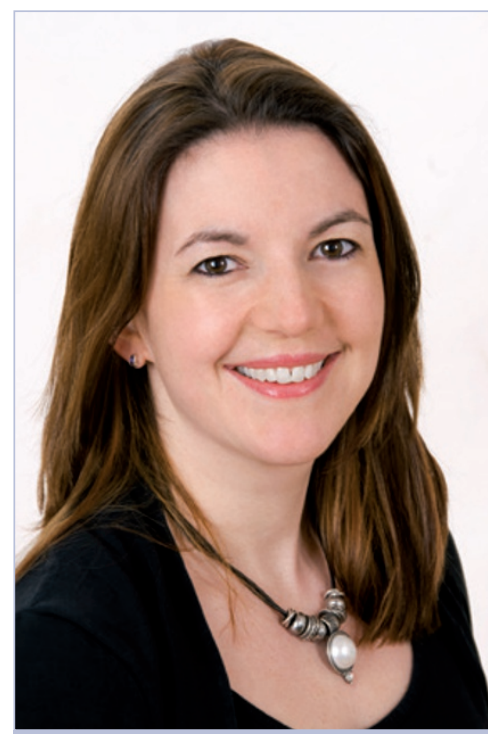

Elaine Halley is a general and cosmetic dentist and the brains behind Cherrybank Dental Spa in Edinburgh and Perth. Not only is she the first cosmetic dentist in Scotland to achieve master's level work in advanced cosmetic dentistry at the Rosenthal Institute in New York, Elaine is also in high demand internationally as a lecturer and is a member of the Editorial Board for Private Dentistry and Aesthetic Dentistry. As well as starting the British Academy of Cosmetic Dentistry, Elaine is also the only dentist in Scotland to achieve accreditation to the BACD.

and appreciate the efforts that we make to look after their well-being.

\section{What's been the proudest} moment in your career so far?

Definitely the formation of the British Academy of Cosmetic Dentistry, serving my year as president and achieving accreditation. Together with my friends and colleagues, Chris Orr and David Bloom, we took an idea that was formed on the back of an envelope, and we made it reality. The Academy has gone from strength to strength and our initial values of open, high level education and inclusiveness to all members of the dental team still prevail. I am very proud of everyone who has been involved over the years.

You're speaking at this year's British Dental Conference and Exhibition about using Digital Smile Design in aesthetic dentistry. What do aesthetic dentists need to consider when planning treatment?

Digital Smile Design (DSD) is a philosophy and a tool for enhanced communication which allows us 
to plan from a facial perspective, and to communicate with specialists and dental technicians to design calibrated options for our patient - whether they are restorative, orthodontic or surgical. The face is the key. We need to hold the horizontal line of the patient's face when we are designing tooth position - and this can easily be lost without DSD. Using readily available technology such as digital photography and video, we can create a blueprint for a smile which works biologically, functionally and aesthetically.

\section{What does the future hold for cosmetic dentistry and Digital Smile Design?}

DSD, led by Christian Coachman, is now being integrated with other software, such as orthodontic planning tools and CADCAM. This is the future - 3D planning but with the face in motion. Emotional photography and design allows us to capture the essence of a patient in a more empathetic way - and be sure that our dentistry is in harmony with their character. The future is very exciting.

\section{Now you've got your masters (congratulations!), any more studying on the horizon?}

Achieving the masters qualification was hard work and the biggest area of learning for me was clinical research. I am finding that more and more complex restorative cases require a level of orthodontics in order to achieve the optimal result - and so I may undertake an orthodontic diploma - but I'm in no hurry to jump into another degree commitment!

\section{With so much going on, how do you spend your spare time?}

I have three children aged 15, 14 and 7 so most of my spare time is spent enjoying their company and interests. I also run - slowly! I run a marathon a year for Parkinson's UK - this year it is New York in November - so I need to step up my training soon!

\section{What would your advice be to newly qualified dentists looking to specialise in cosmetic dentistry?}

I would advise young dentists to get some general dental practice experience under their belts. Cosmetic dentistry is not a specialty in its own right but falls under the remit of restorative dentistry and the mantra should always be minimal intervention. Also, I would recommend they invest in their ongoing education. I advise that my new associates attend courses such as those run by Advanced Dental Seminars and Christopher Orr or by Paul Tipton. Also to travel - attend conferences and courses in other countries and follow the best thinkers in our profession such as Pascale Magne, Newton Fahl, John Kois and Frank Spear to name but a few. It is also important to understand health, function and biology which all have to come before aesthetics. Learn to take photographs, diagnose correctly, communicate with patients, attend study clubs and meet with like-minded people, eg by joining the British Academy of Cosmetic Dentistry and following their accreditation pathway. Continuous learning and 'learn to walk before you can run' are all important principles to live by.

\section{What area of dentistry gives you the most job satisfaction?}

I enjoy diagnosing, treatment planning and communication with patients. Every mouth has a different story to tell and I love using DSD principles to assist with the challenge of figuring out what has happened and how to put things right. This is coupled with educating the patient and the 'co-discovery' of allowing them to take ownership of their mouths and their futures. In technical terms, I enjoy minimal prep porcelain work as the beauty of recreating nature can be very satisfying.

\section{I get the impression you've} travelled a lot with your career where's your favourite place to go?

I do love travelling - particularly to new places. I love the fact that the pursuit of excellence in dentistry can take me to places I would never normally go! I enjoy travelling in Europe, but for motivation in dentistry I cannot look past the US - particularly the American Academy of Cosmetic Dentistry annual conference. They really showcase many of the profession's best speakers and I often take team members with me as they cater very well for the entire team. We always return motivated and ready for action!

INTERVIEW BY ANNABEL NICHOLSON

Elaine Halley will present a talk entitled 'Digital Smile Design - the emotional connection' on Friday 8 May at the 2015 British Dental Conference and Exhibition in Manchester. Register online: www.bda.org/conference. Three-day VIP conference passes are free to Extra and Expert BDA members. 